\title{
ANÁLISE HIDROQUÍMICA DOS AQUÍFEROS GUARANI E SERRA GERAL NO MUNICÍPIO DE IBIPORÃ-PR
}

\author{
André Celligoi \\ Universidade Estadual de Londrina, Departamento de Geociências, Londrina, PR, Brasil \\ celligoi@uel.br \\ Josilaine Amancio Corcóvia \\ Universidade Estadual de Londrina, Pós-Graduação em Geografia, Londrina, PR, Brasil \\ lainecorcovia@gmail.com \\ José Paulo Peccinini Pinese \\ Universidade Estadual de Londrina, Departamento de Geociências, Londrina, PR, Brasil \\ pinese@uel.br
}

\begin{abstract}
RESUMO
Os sistemas aquíferos Serra Geral (SASG) e Guarani (SAG) se constituem aquíferos mais importantes do Estado do Paraná, principalmente em função da qualidade química e potencialidade de produção. Este trabalho apresenta a análise de dois poços do Sistema Aquífero Guarani e vinte e cinco poços do Sistema Aquífero Serra Geral situados no município de lbiporã - PR, tendo como objetivo principal a caracterização dessas águas em termos de comportamento químico. Foram efetuados levantamentos da área de estudo através de trabalhos de campo. Os parâmetros químicos analisados foram: bicarbonato, carbonato, cloreto, fluoreto, nitrato, nitrito e sulfato. Para análise destes parâmetros foram utilizados os métodos de: espectometria UV, turbidimetria e titulação com nitrato de prata. Para analisar possíveis conexões entre o SAG e o SASG, foi elaborado o diagrama de Piper para as amostras da área. Alterações na concentração desses parâmetros podem causar danos à saúde humana, pois muitas vezes a água do SASG possui um elevado nível de fluoreto em sua composição. Como resultados, foram identificados padrões anômalos de fluoreto nos poços do SAG que pode influir na saúde da população local, mas que não ultrapassaram os limites permitidos pela RESOLUÇÃO CONAMA 396/2008 e a PORTARIA 2914/2011 do Ministério da Saúde, devendo esses padrões ser analisados com frequência.
\end{abstract}

Palavras-chave: Águas subterrâneas. Paraná. Hidrogeoquímica. Consumo humano.

\section{HYDROCHEMICAL ANALYSIS OF GUARANI AND SERRA GERAL AQUIFERS IN THE MUNICIPALITY OF IBIPORÃ-PR}

\begin{abstract}
The Serra Geral (SASG) and Guarani (SAG) aquifer systems are the most important aquifers in the state of Paraná, mainly due to their excellent chemical quality and production potential. This paper presents the analysis of two wells of the Guarani Aquifer System (SAG) and twenty-five wells of Serra Geral Aquifer System (SASG) located in the municipality of lbiporã - PR, having as main objective the characterization of groundwater chemical parameters. Field work was carried out to survey the study area. The chemical parameters were analyzed: bicarbonate, carbonate, chloride, fluoride, nitrate, nitrite, and sulfate, and to analyze these parameters were used different methods as UV spectroscopy, turbidimetry and titration with silver nitrate. Piper diagram was developed in order to analyze possible connections between SAG and the SASG. Changes in the concentration of these parameters can cause harm to human health, since often the water from SGAS has a fluorine increase in its composition. As a result, anomalous fluorine patterns were identified in the SAG wells, but not exceeding the limits permitted by CONAMA RESOLUTION 396/2008 and 2914/2011 Ordinance of the Ministry of Health.
\end{abstract}

Keywords: Groundwater. Paraná. Hidrogeochemistry. Human consumption.

$\begin{array}{llllll}\text { Caminhos de Geografia } & \text { Uberlândia } & \text { v. 20, n. } 72 & \text { Dez/2019 } & \text { p. 77-93 } & \text { Página } 77\end{array}$




\section{INTRODUÇÃO}

O desenvolvimento econômico e populacional tem desencadeado uma demanda progressiva de água para consumo doméstico e industrial. $O$ aproveitamento da água subterrânea, durante os últimos anos, tem sido utilizado cada vez em maior quantidade como fonte complementar no sistema de abastecimento, tanto pelo setor industrial, quanto por particulares, incluindo entre outros, condomínios residenciais e atividades ligadas ao comércio (CELLIGOI e DUARTE, 1997).

Os empreendimentos industriais apresentam potencial capacidade de contaminação dos solos e da água subterrânea, principalmente as atividades dos setores de produção têxtil, alimentícia, gráfica, química, metalúrgica, siderurgia, celulose, minerais metálicos e não-metálicos, farmacêuticos, dentre outros (ALIEVI et al., 2019). A água tóxica não depende somente da interação de uma espécie química, mas também da interação de diferentes condições e espécies químicas e físicas que podem resultar na redução ou acentuação dos efeitos tóxicos (BRANCO, 1999). Os poços construídos, operados e abandonados sem controle podem se transformar em verdadeiros focos de poluição das águas subterrâneas que são extraídas, sobretudo, daqueles localizados no meio urbano.

Existem padrões conhecidos entre a incidência de moléstias no homem e nos animais e o aumento ou diminuição de constituintes na água que é ingerida por esses indivíduos (BRANCO, 1999). O bócio que ocorre devido à baixa concentração de iodo, a fluorose dentária e óssea/esqueletal devido ao excesso de flúor, nanismo e hiperpigmentação da pele provocado pela deficiência de zinco, podem ser citados como exemplos. Há outras ocorrências que ainda geram controvérsias no meio científico como, por exemplo, a dureza da água e sua relação com doenças cardiovasculares, o excesso de chumbo com a esclerose múltipla, o cádmio a hipertensão. A Organização Mundial de Saúde (OMS) permite apenas $1,5 \mathrm{mg} \mathrm{L}^{-1}$ como limite seguro de flúor na água potável (TAMER, 2019).

Com o intuito de se estabelecer as condições de qualidade de uma água potável, são adotados os limites descritos pelas seguintes legislações:

a) A Portaria № 2914/2011 (Brasil, 2011), do Ministério da Saúde, é de uso obrigatório em todo território nacional. b) A Resolução RDC № 274/2005, da Agência Nacional de Vigilância Sanitária (ANVISA), órgão vinculado ao Ministério da saúde. (ROSA FILHO et al., 2010).

c) A Resolução №396/2008 (Brasil, 2008), do Conselho Nacional de Meio Ambiente (CONAMA), pertencente ao Ministério de Meio Ambiente. Esta resolução dispõe sobre a classificação e diretrizes ambientais para o enquadramento das águas subterrâneas (Brasil, 2008).

Os valores máximos permissíveis especificados nesta resolução referem-se às águas originárias de mananciais destinadas ao abastecimento, para o consumo humano, após desinfecção, e à preservação do equilíbrio natural das comunidades aquáticas (ROSA FILHO et al., 2010).

Apesar de todos estes benefícios, as águas subterrâneas também apresentam algumas desvantagens, como a questão da detecção e identificação de fontes de contaminação, seja ela de origem natural, ou antrópica; a manutenção periódica mais cara, devido à multiplicidade de equipamentos de bombeamento; em geral, maior consumo de energia elétrica neste sistema.

A qualidade da água é definida por sua composição e pelo conhecimento dos efeitos que seus constituintes podem causar, que se dividem em constituintes maiores, quando estão presentes com teores superiores a $5 \mathrm{mg} / \mathrm{L}$; menores, quando os teores ficam entres $0,01 \mathrm{e} 10 \mathrm{mg} / \mathrm{L}$; e traços, quando os teores são inferiores a $0,01 \mathrm{mg} / \mathrm{L}$.

Conforme Feitosa et al. (2009), os processos e fatores que influem na evolução da qualidade das águas subterrâneas podem ser intrínsecos e extrínsecos ao aquífero. Devido ao escoamento lento em diferentes aquíferos, a água subterrânea tende a aumentar concentrações de substâncias dissolvidas presentes no meio, onde, além deste interferente, temos alguns outros fatores que podem influenciar na sua qualidade como: clima, composição da água de recarga, tempo de contato água/meio físico, litologias atravessadas, além da contaminação do homem.

Este trabalho visa caracterizar hidroquimicamente os aquíferos Guarani e Serra Geral no município de Ibiporã-PR, a fim de verificar uma possível relação de conectividade, analisando a qualidade da 
água desses aquíferos para a população que está fazendo seu uso para fins de abastecimento, propondo uma análise dos recursos hídricos do município e observando as leis vigentes no país sobre a temática.

\section{Aspectos fisiográficos e hidrogeológicos da área de estudo}

O município de Ibiporã (Figura 1) está localizado na microregião de Londrina, Norte Paranaense, na sub-bacia do rio Tibagi o qual nasce nos Campos Gerais, sendo o principal afluente do rio Paranapanema. Os rios que drenam o município são Tibagi, Ribeirão Engenho de Ferro e Ribeirão Jacutinga. O Ribeirão Jacutinga serve como manancial superficial e os sistemas aquíferos Serra Geral (SASG) e Guarani (SAG) como manancial subterrâneo, sendo empregados para captação e abastecimento de água para a população da cidade. Tal abastecimento se dá com aproximadamente $50 \%$ de água superficial e o restante através dos dois poços do aquífero Guarani, enquanto que 25 poços são do SASG. Este último é mais utilizado nas áreas rurais do município, como observado na Figura 2.

Figura 1 - Mapa de localização da área de estudo.

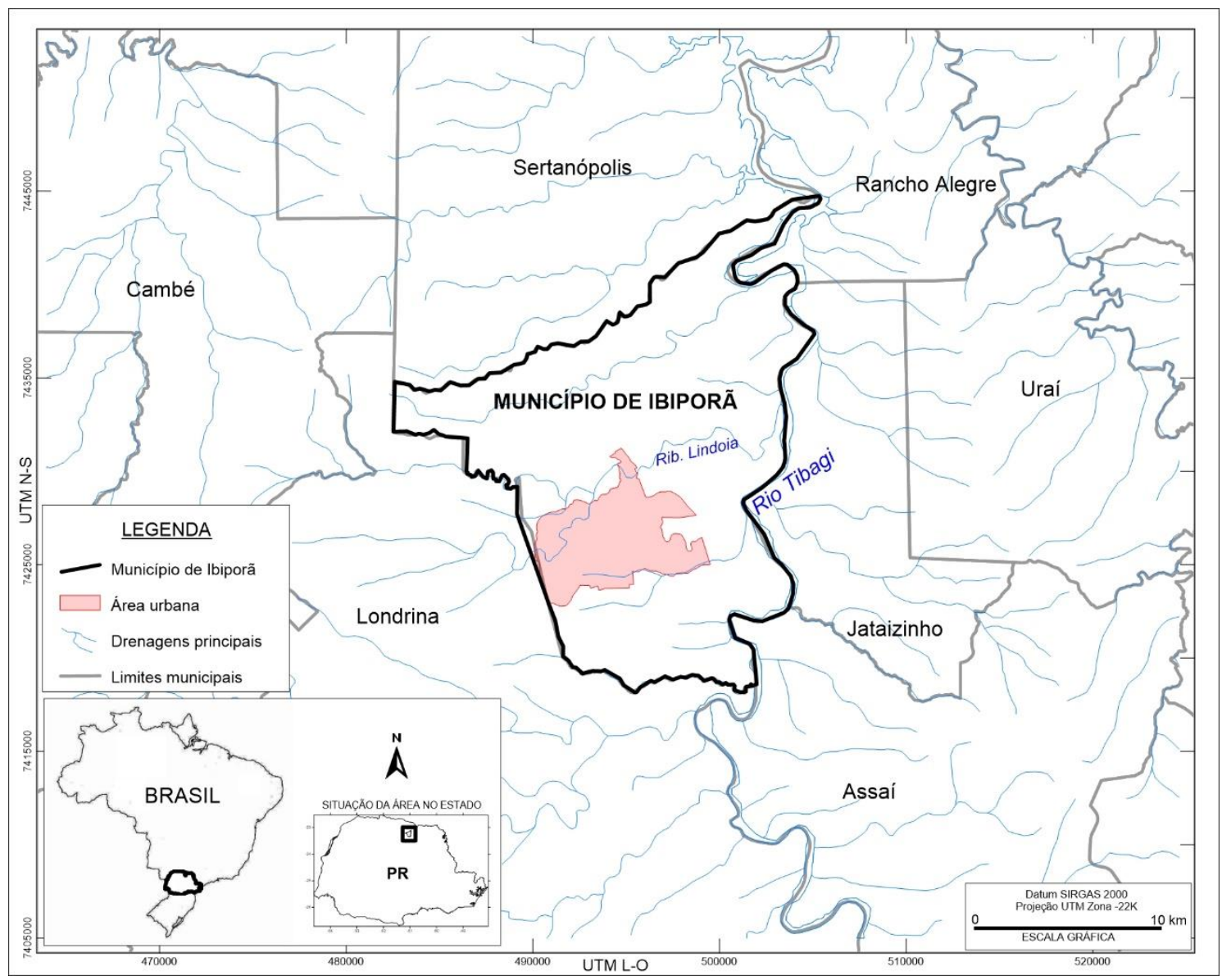

Fonte - Base de dados ITCG.

O relevo da sede do município é também ondulado com declividades acentuadas próximas as nascentes de córregos, chegando às vezes a declividades superiores a $20 \%$. O regime de ventos dominantes provém do quadrante sul, $18,2 \%$ ao sul e 22,9\% sudoeste (CORCÓVIA, 2013).

O SAG, um dos maiores reservatórios de águas subterrâneas do mundo, é considerado no Brasil como alojado no conjunto das formações Botucatu e Piramboia (ARAÚJO, 1995). Em algumas regiões, este manancial armazena água com alguns parâmetros físico-químicos que ultrapassam os
Caminhos de Geografia
Uberlândia
v. 20, n. 72
Dez/2019
p. $77-93$
Página 79 
limites mínimos estabelecidos para o abastecimento público (AMORE et al., 2001). Na área de estudo este aquífero não é aflorante na superfície, ocorrendo a uma profundidade de aproximadamente 850 metros, abaixo das rochas eruptivas básicas da Formação Serra Geral.

As águas do SAG são geralmente potáveis apresentando baixa mineralização na sua área de recarga e pequenas velocidades de circulação. Entretanto, há ocorrências de flúor, arsênio, e salinidade elevada em algumas localidades (HINDI, 2007). São do tipo bicarbonatadas cálcicas, com evolução das águas para bicarbonatadas sódicas e, em certos setores, a cloretadas sódicas. Localmente há altas concentrações de sulfatos. Assinalam-se áreas restritas onde a pequena circulação parece estar associada à maior salinidade das águas (estados do Paraná, Santa Catarina e Rio Grande do Sul).

De acordo com Rebouças (1996), no extremo sul do SAG registram-se áreas com alta salinidade. O mesmo é observado nas regiões argentinas no limite oeste do Aquífero. As águas do SAG na SubBacia Norte apresentam-se saturadas em calcita, exceto nas zonas de recarga, e não saturadas em sílica. Destaca-se que a evolução das águas nas áreas confinadas profundas gera, como resultado, águas de elevados $\mathrm{pHs}$ e de maior temperatura, entretanto todas respondem a gradiente geotérmico normal.

O SASG corresponde às zonas aquíferas das rochas basálticas da Formação Serra Geral.

\begin{abstract}
"Essas rochas apresentam, via de regra, textura microcristalina, estrutura maciça e vesicular e/ou amigdaloidal, bem como intenso fraturamento. Esfoliações esferoidais são características marcantes dos basaltos, tanto maciços, quanto vesicoamigdalidais, embora sejam mais raras nestes últimos". (CELLIGOI, 1993, p. 23)
\end{abstract}

Devido às suas características litológicas, não possuem porosidade e permeabilidade primárias. Assim sendo, para o armazenamento e condução da água, devem ocorrer descontinuidades físicas na rocha, de forma a constituir um meio aquífero fisicamente heterogêneo e anisotrópico (REBOUÇAS, 1988), que se caracteriza por uma condutividade hidráulica muito variável, complexa e de difícil avaliação, característica de um sistema aquífero fraturado (FRAGA, 1986; 1992).

Conforme estudos realizados nesse contexto, Fraga (1986; 1992), Rosa Filho et al. (1987), Celligoi e Duarte (1994) determinam que a tipologia característica para a água presente nas rochas basálticas é bicarbonatada cálcica, relacionada com a mineralogia e natureza química dessas rochas. Os dois primeiros autores admitem que a composição bicarbonatada sódica de algumas águas de poços neste ambiente sugere mistura com as águas de aquíferos subjacentes, a exemplo do Sistema Aquífero Guarani e aquíferos paleozóicos.

O SASG está associado às rochas vulcânicas da Formação Serra Geral e suas águas são bicarbonatadas cálcicas ou magnesianas, com concentrações variáveis de cálcio, magnésio, sódio, carbo-natos, bicarbonatos, condutividade inferiores a $200 \mathrm{uS} / \mathrm{cm}$ e pH menores que 7,5. No entanto, ocorrências de águas no SASG classificadas como bicarbonatadas sódicas a sulfatadas cálcicas ou magnesianas, associadas ao aumento na concentração de sódio, potássio, carbonatos, bicarbonatos, cloretos, sulfatos, $\mathrm{pH}$ e condutividade elétrica, parece indicar a possibilidade de existência de uma conexão entre as duas unidades, que pode existir nas regiões onde há maior grau de fraturamento e menor espessura do pacote de rochas vulcânicas REGINATO et al (2013).

\title{
METODOLOGIA
}

\section{Levantamento de dados e cadastramentos dos poços}

A etapa de levantamento de dados envolveu a coleta de material bibliográfico, aspectos socioeconômicos e dados relativos aos poços existentes no município de lbiporã que exploram o Aquífero Guarani e o Aquífero Serra Geral. Os dados solicitados às empresas foram referentes à localização dos poços perfurados, data de perfuração e nome dos proprietários, vazão, profundidade, nível estático e nível dinâmico. Foram obtidos dados cadastrais sobre 40 poços na zona urbanizada e de expansão no município de Ibiporã, em que 27 poços foram devidamente

$\begin{array}{lllll}\text { Caminhos de Geografia } & \text { Uberlândia } & \text { v. 20, n. } 72 & \text { Dez/2019 } & \text { p.77-93 Página } 80\end{array}$


localizados e verificados em campo, sendo então plotados em mapa (Figura 2).

Neste cadastramento, foram observados os dados dos poços referentes à profundidade total, a qual aquífero pertence, e identificado o proprietário; também, as características hidráulicas do aquífero, como níveis estático e dinâmico e dados de produção.

As localizações dos poços da área foram obtidas através de trabalhos de campo, sendo que dos 27 poços analisados na pesquisa, dois são de propriedade do SAMAE (Sistema Autônomo Municipal de Água e Esgoto) e utilizados no abastecimento público e o restante, de particulares, sendo destinados ao uso industrial, doméstico e comercial.

\section{Trabalhos de campo e procedimentos}

Os trabalhos de campo foram realizados em duas etapas, com o objetivo de obtenção de coordenadas geográficas dos poços identificados anteriormente, através das informações cadastradas pelas empresas perfuradoras, bem como a coleta de água para as análises químicas. Também foram utilizadas imagens de satélites para a observação da paisagem, uso do solo, rede hidrográfica e urbanização, auxiliando em estudos posteriores e na confecção de mapas. Os dados coletados possibilitaram o entendimento de como o uso do solo pode interferir na qualidade da água do município estudado.

As amostras foram coletadas em frascos de polietileno de 2 litros, entre os dias de 02 a 06 de agosto de 2011, enxaguadas pelo menos cinco vezes com a água do poço e mantidas em caixa de isopor com gelo até a chegada ao laboratório. As mesmas foram levadas à câmara fria do Departamento de Química da Universidade Estadual de Londrina, onde em novembro foram realizadas as análises. Esse longo período entre a coleta e a análise tornou necessário realizar uma nova coleta que ocorreu entre os dias 1 a 4 de março de 2012, para análises de carbonato, bicarbonato e sulfato, além desses elementos, também foram analisados cálcio, cloreto, flúor, nitratos e nitritos através do laboratório SEBRAQ (Serviço Brasileiro de Análises Ambientais e Químicas e Biológicas). Essas análises seguiram a metodologia de Rice et al. (2012).

\section{Metodologia Analítica}

Os dados analíticos da qualidade da água foram realizados pelos métodos relacionados na tabela 1.

Tabela 1 - Método analítico empregado na pesquisa.

\begin{tabular}{lr}
\hline PARÂMETRO & MÉTODO DE ANÁLISE \\
\hline $\begin{array}{lr}\text { Bicarbonato } \\
\text { Cálcio }\end{array}$ & Titulometria (argentométrico) \\
Carbonato & Absorção Atômica \\
Cloreto & Titulação com nitrato de prata \\
Fluoreto & Titulometria (argentométrico) \\
Magnésio & Turbidimetria \\
Nitrato & Absorção Atômica \\
Nitrito & Espectrometria UV \\
Potássio & Espectrometria UV \\
Sódio & Fotometria de emissão de chama \\
Sulfato & Fotometria de emissão de chama \\
\hline & Turbidimetria \\
\hline
\end{tabular}


Figura 2 - Distribuição dos poços dos Sistemas aquíferos Serra Geral e Guarani no município de Ibiporã-PR.

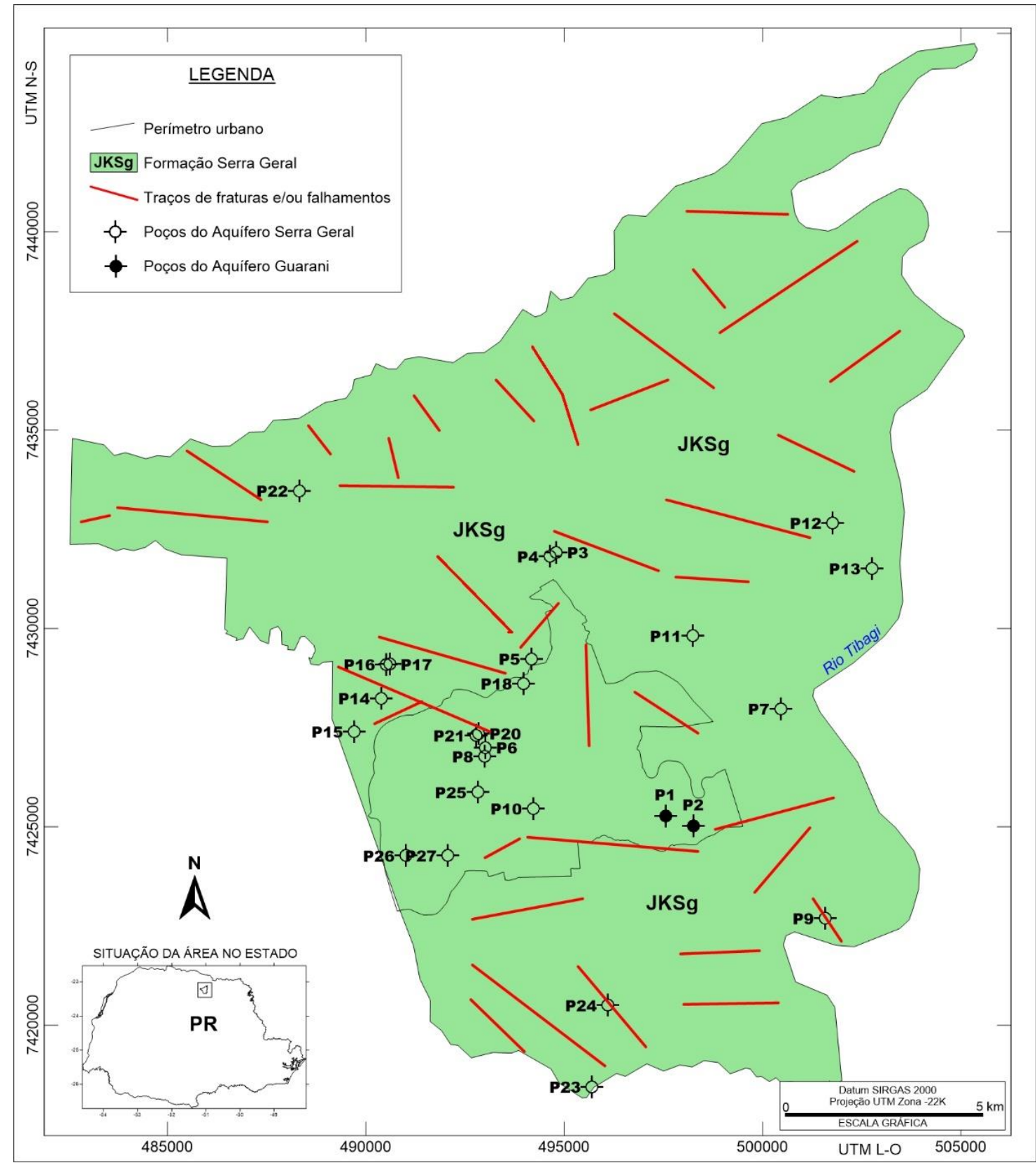

Fonte: Prefeitura Municipal de Ibiporã (2017). A localização dos poços foi obtida nos trabalhos de campo em 2012

\section{Análise de dados hidroquímicos}

Os dados de análises de água obtidos através de trabalho de campo e dados pré-existentes das empresas perfuradoras de poços foram analisados a partir de um conjunto de dados referentes à área de estudo que engloba os Aquíferos Guarani e Serra Geral. Os dados foram plotados em diagramas de Piper, buscando-se separar os tipos das águas, verificando qual a tendência de cada zona.

O diagrama de Piper foi utilizado para classificação e comparação de distintos grupos de águas quanto aos cátions e ânions dominantes, mostrando, assim, as proporções relativas dos íons principais, mas não suas concentrações absolutas. 


\section{RESULTADOS E DISCUSSÕES}

Conforme a Tabela 2, foram analisados 27 poços (figuras 3 e 4), sendo que dois (P1 e P2) pertencem ao SAMAE e são provenientes do SAG. Os demais poços são de propriedades particulares e provenientes do SASG.

Também a Tabela 2 apresenta os resultados obtidos para todos os pontos dos poços tubulares, tendo como valores de referência os descritos na portaria n² 2914/2011 (BRASIL, 2011).

Tabela 2 - Parâmetros químicos analisados (valores em mg/L).

\begin{tabular}{|c|c|c|c|c|c|c|c|c|c|c|c|}
\hline ÍONS & $\mathrm{Na}^{+}$ & $\mathrm{K}^{+}$ & $\mathbf{M g}^{2+}$ & $\mathrm{Ca}^{2+}$ & $\mathrm{HCO}_{3}-$ & $\mathrm{CO}_{3}^{-}$ & $\mathrm{Cl}^{-}$ & $\mathrm{F}^{-}$ & $\mathrm{NO}_{3}^{-}$ & $\mathrm{NO}_{2}^{-}$ & $\mathrm{SO}_{4}^{2-}$ \\
\hline VMP & 200 & 20 & 10 & 500 & --- & --- & 250 & 1,5 & 10 & 1,0 & 250 \\
\hline \multicolumn{12}{|l|}{ Poços } \\
\hline $\mathrm{P}^{*}{ }^{*}$ & 18,74 & 0,07 & 0,69 & 0,40 & 30,30 & 60,60 & 4,89 & 0,13 & ND & 0,01 & 3,89 \\
\hline $\mathrm{P} 2^{*}$ & 17,44 & 0,07 & 0,79 & 0,41 & 32,31 & 62,30 & 4,89 & 0,14 & ND & 0,01 & 3,58 \\
\hline P3 & 1,12 & ND & 5,19 & 0,10 & 18,18 & ND & 3,08 & 0,05 & ND & 0,02 & ND \\
\hline P4 & 7,65 & ND & 2,39 & 12,50 & 84,84 & ND & 3,44 & 0,05 & ND & 0,02 & ND \\
\hline P5 & 10,67 & ND & 1,65 & 5,70 & 70,70 & 16,16 & 10,86 & 0,03 & ND & 0,01 & ND \\
\hline P6 & 5,04 & ND & 5,19 & 12,00 & 124,50 & ND & 5,43 & 0,02 & ND & 0,01 & ND \\
\hline P7 & 9,36 & ND & 5,74 & 16,07 & 105,24 & ND & 2,23 & 0,11 & ND & 0,01 & ND \\
\hline P8 & 3,33 & ND & 5,12 & 9,99 & 173,68 & ND & 2,90 & 0,02 & ND & 0,01 & ND \\
\hline P9 & 7,85 & ND & 1,65 & 9,90 & 105,04 & ND & 2,17 & 0,09 & ND & 0,01 & ND \\
\hline P10 & 3,39 & ND & 2,13 & 13,00 & 101,00 & ND & 2,02 & 0,05 & ND & 0,01 & ND \\
\hline P11 & 4,94 & ND & 1,65 & 13,50 & 101,00 & ND & 4,16 & 0,05 & ND & 0,01 & ND \\
\hline $\mathrm{P} 12$ & 15,59 & ND & 2,13 & 13,00 & 90,90 & 20,20 & 8,33 & 0,11 & ND & 0,11 & 2,43 \\
\hline P13 & 7,05 & ND & 5,74 & 9,00 & 94,94 & ND & 8,69 & 0,03 & ND & 0,02 & ND \\
\hline P14 & 8,06 & ND & 1,74 & 16,20 & 96,96 & ND & 4,89 & 0,11 & ND & 0,01 & ND \\
\hline P15 & 14,06 & ND & 1,74 & 1,50 & 42,42 & ND & 11,59 & 0,19 & 2,32 & 0,20 & ND \\
\hline P16 & 7,12 & ND & 1,45 & 16,50 & 145,44 & ND & 2,08 & 0,11 & ND & 0,20 & ND \\
\hline P17 & 10,87 & ND & 2,13 & 21,28 & 5,05 & ND & 3,26 & 0,09 & ND & 0,02 & ND \\
\hline P18 & 13,73 & ND & 0,14 & 6,00 & 145,44 & ND & 12,31 & 0,05 & ND & 0,02 & ND \\
\hline P19 & 5,97 & ND & 1,78 & 20,10 & 135,34 & ND & 8,87 & 0,08 & ND & 0,01 & ND \\
\hline P20 & 5,97 & ND & 1,78 & 20,10 & 135,34 & ND & 8,87 & 0,08 & ND & 0,01 & ND \\
\hline P21 & 2,13 & ND & 1,78 & 2,80 & 36,36 & ND & 4,53 & 0,03 & ND & 0,01 & ND \\
\hline P22 & 3,13 & ND & 0,14 & 12,40 & 48,48 & 16,16 & 5,25 & 0,05 & ND & 0,02 & 5,49 \\
\hline P23 & 10,77 & ND & 0,51 & 7,30 & 68,68 & ND & 3,26 & 0,11 & ND & 0,01 & ND \\
\hline P24 & 7,75 & ND & 1,78 & 23,90 & 167,66 & ND & 2,35 & 0,10 & ND & 0,02 & ND \\
\hline P25 & 13,58 & ND & 0,81 & 1,00 & 22,22 & 32,32 & 3,62 & 0,43 & ND & 0,01 & 5,76 \\
\hline P26 & 8,66 & ND & 0,81 & 0,80 & 38,38 & 48,48 & 3,44 & 0,29 & ND & 0,01 & 0,29 \\
\hline P27 & 18,2 & ND & 1,45 & 1,30 & 10,10 & 24,24 & 22,45 & 0,35 & ND & 0,01 & 0,29 \\
\hline
\end{tabular}


Os resultados hidrogeoquímicos das análises da área de estudo foram comparados com as resoluções Portaria 2914 (BRASIL, 2011) e CONAMA 396 (BRASIL, 2008) para verificar se essas águas subterrâneas se encontram de acordo com os parâmetros de qualidade de água exigidos conforme legislação vigente.

\section{Bicarbonato}

Os valores de concentração de bicarbonatos mostraram-se inferiores ao limite permitido para águas subterrâneas, que é de $1000 \mathrm{mg} / \mathrm{L}$. As amostras analisadas possuem valores máximo de 173,68 mg/L no poço P8 (SASG) e mínimo de 5,05 mg/L no poço P17 (SASG) (Tabela 2). Sendo que os os poços 1 e 2 do SAG encontram-se dentro do limite permitido pela Portaria 2914/2011.

$\mathrm{Na}$ Figura 3 são verificadas suas frequências e distribuição. Segundo Ayers e Westcot (1985), a dureza de uma água é proporcional à presença de sais de cálcio e magnésio, a qual pode ser temporária quando devido à presença de bicarbonatos de cálcio e magnésio ou permanente, quando originada por cloretos, sulfatos e nitratos de cálcio e magnésio. A quantidade de cálcio é duas vezes maior do que a de magnésio, porém estes valores variam muito de local para local.

Figura 3 - Isolinhas da distribuição dos teores de bicarbonato nas águas dos poços.

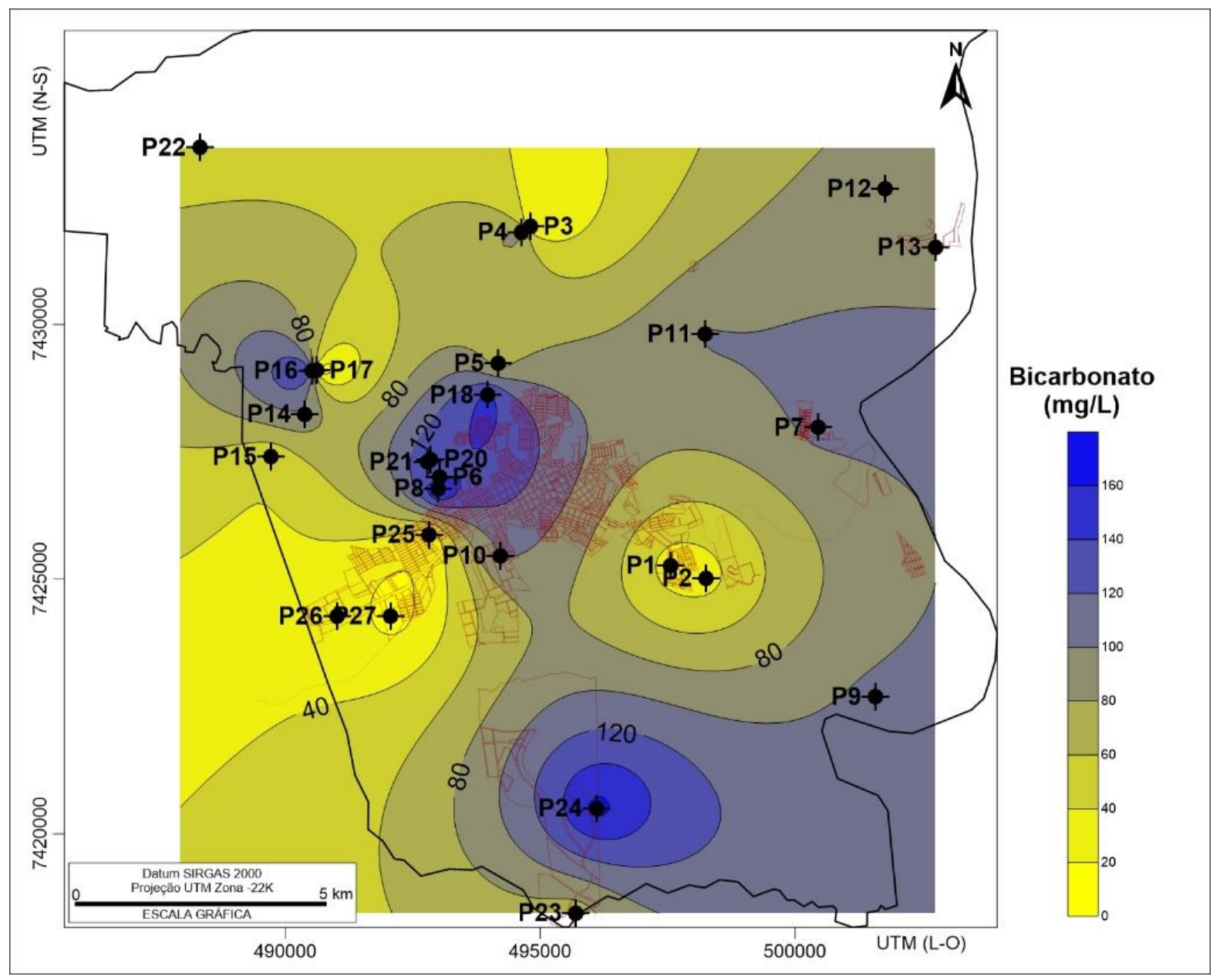

Fonte-CORCÓVIA (2013). 


\section{Carbonato}

Nas amostras analisadas, dados expressos anteriormente na Tabela 2, mais de $50 \%$ dos resultados estão abaixo do limite detectado pela técnica analítica. De acordo com Corcóvia (2013), o valor máximo foi de $60,60 \mathrm{mg} / \mathrm{L}$ nos poços do Aquífero Guarani (P1 e P2) e mínimo abaixo dos limites de detecção nos poços do Aquífero Serra Geral, (Figura 4).

Em se tratando do carbonato de sódio, o mesmo é utilizado em fotografia, em limpezas, no controle do $\mathrm{pH}$ da água, no tratamento têxtil, como aditivo alimentar, na fabricação de vidros, sabão, tintas, papel, corantes e no tratamento da água de piscinas.

Vale ressaltar que a Portaria 2914/2011 do Ministério da Saúde não identifica os limites máximos e mínimos para consumo humano.

Figura 4 - Isolinhas da distribuição dos teores de carbonato nas águas dos poços.

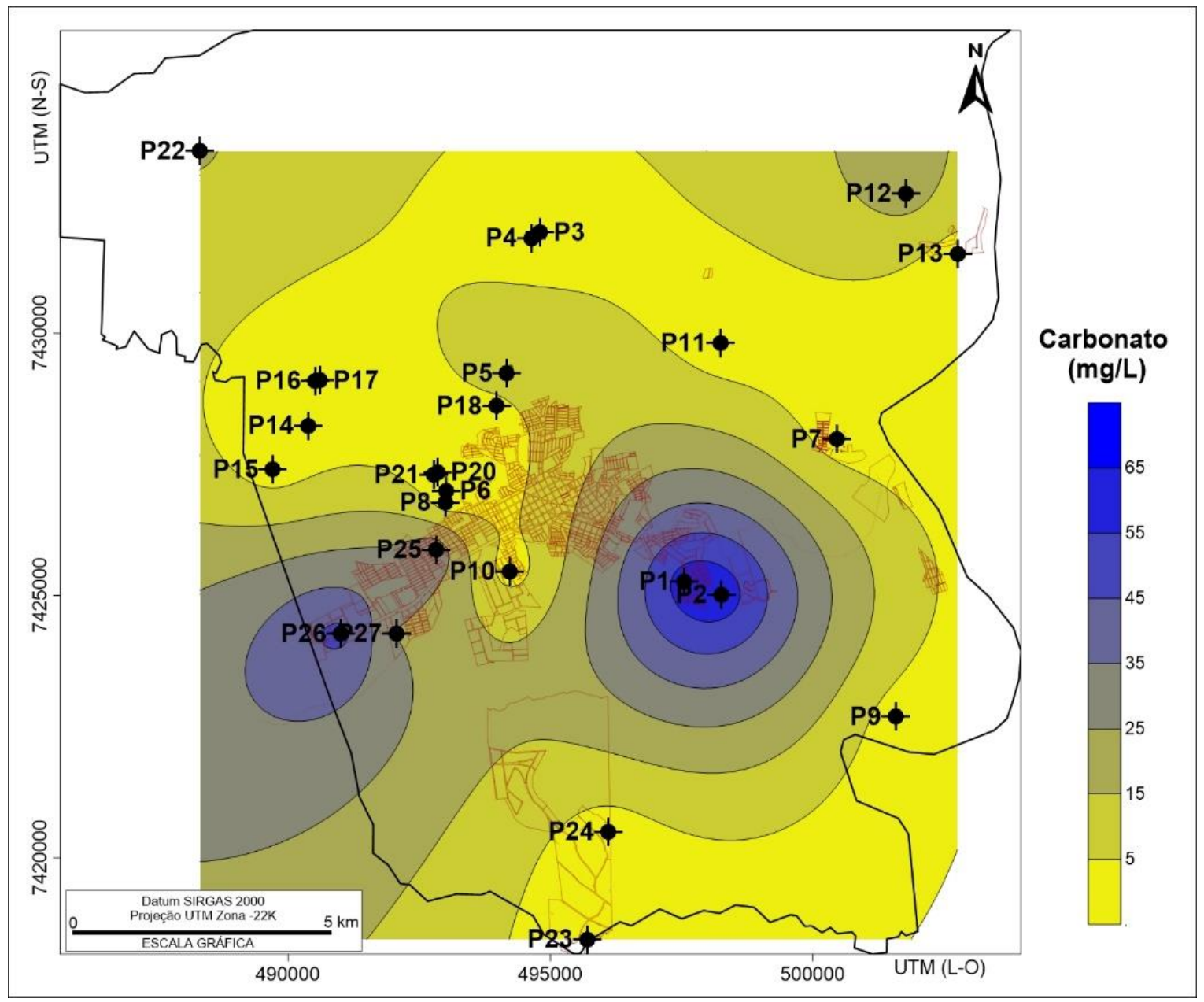

Fonte - CORCÓVIA (2013)

\section{Cloreto}

A portaria no2914/2011 do Ministério da Saúde estabelece o teor de $250 \mathrm{mg} / \mathrm{L}$ como o valor máximo permitido para água potável. Deve-se frisar que "os métodos convencionais de tratamento de água não removem cloretos. A sua remoção pode ser feita por desmineralização (deionização) ou evaporação" (BRASIL, 2011).

Analisando as amostras dos poços do SAG e SASG através da Tabela 2 e Figura 5, pode-se verificar que a máxima encontrada foi de 24,24 mg/L (P27) e a mínima de 2,02mg/L (P10), com média de 4,89

$\begin{array}{lllll}\text { Caminhos de Geografia } \quad \text { Uberlândia } & \text { v. 20, n. } 72 & \text { Dez/2019 } & \text { p. 77-93 } & \text { Página } 85\end{array}$


$\mathrm{mg} / \mathrm{L}$, salientando que os poços 1 e 2 pertencem ao SAG, as quais não atingiram $4 \mathrm{mg} / \mathrm{L}$. Vale ressaltar que todas as 27 amostras analisadas encontram-se dentro do limite permitido para água potável de acordo com a portaria 2914/2011 do Ministério da Saúde.

Figura 5 - Isolinhas da distribuição dos teores de cloreto nas águas dos poços.

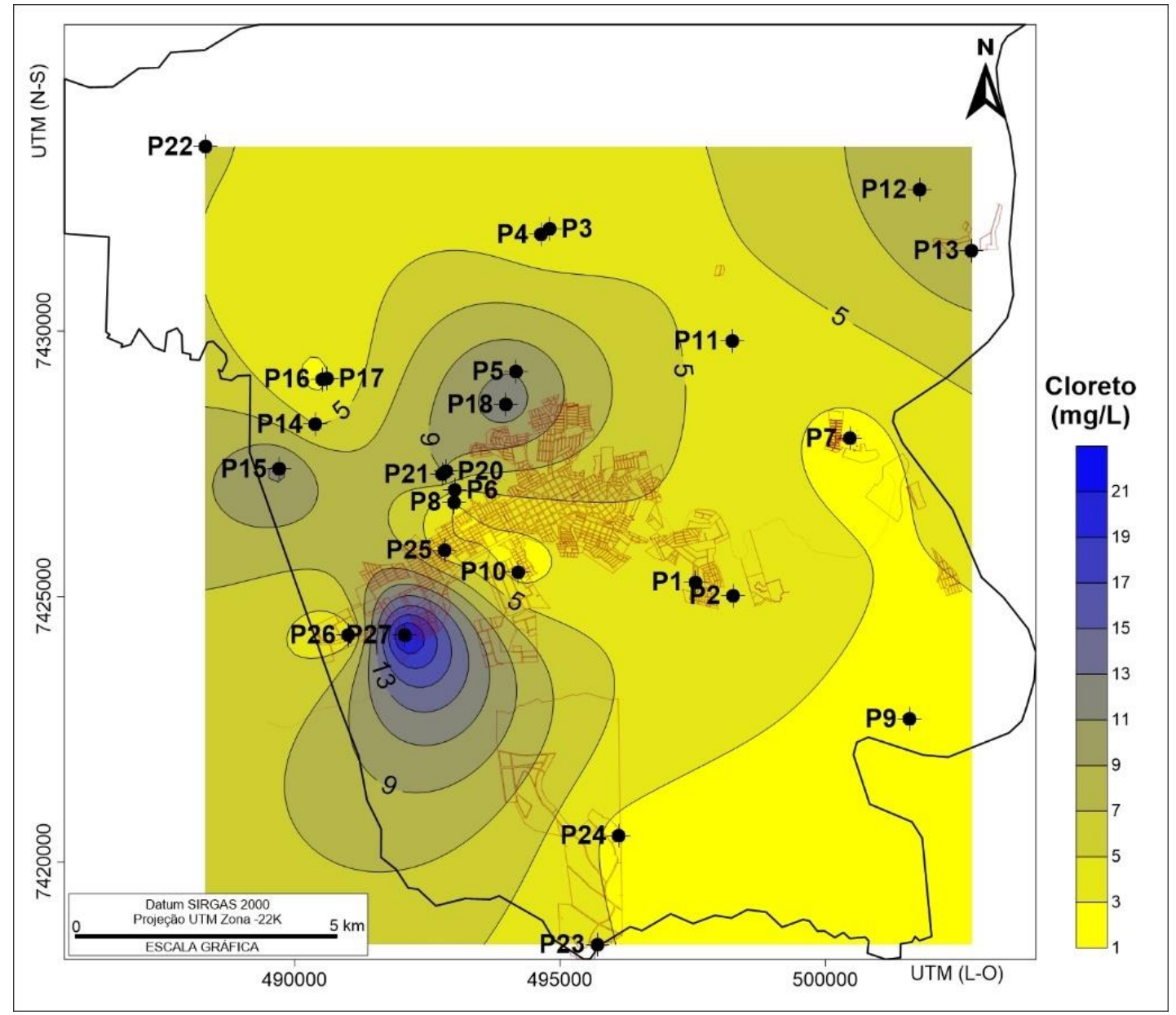

Fonte - CORCÓVIA (2013)

\section{Fluoreto}

Segundo Marimon (2006), o flúor é um elemento essencial aos mamíferos, pois promove o endurecimento da matriz mineral, a base de apatita, dos dentes e esqueleto. $O$ teor ddo como ideal na água potável é dado pela Organização Mundial da Saúde em seria de 0,6 a 0,9 mg/L para países tropicais, embora o CONAMA aceite valores de até $1,5 \mathrm{mg} / \mathrm{L}$ como tolerável para consumo no Brasil se não houver tecnologia de custo-benefício aceitável para ajuste/remoção do seu excesso.

A Tabela 2 e Figura 7, mostra que as máximas estão entre o P27 e P10 do SASG. A mínima encontrada foi de $0,02 \mathrm{mg} / \mathrm{L}$ (P6). Nos poços 25,26 e 27, os teores de fluoreto não estão acima do limite permitido pela legislação vigente, mas que estão acima da média para a área. Eles pertencem ao SASG, são utilizados para irrigação e para consumo humano.

ANA (2005) retratou de forma geral a qualidade das águas subterrâneas no Brasil.

"Teores elevados de fluoreto, acima de $5 \mathrm{mg} / \mathrm{L}$, têm sido detectados em alguns poços de grande profundidade que captam o SAG confinado (FGV, 1998), como em Londrina (PR) e Presidente Prudente (SP). Elevadas concentraçõesmuitas vezes inviabilizam o uso da água para consumo humano." (ANA, 2005, p.23) 
Fraga (1992) aponta que o enriquecimento em fluoreto em águas subterrâneas seja resultado da interação água-rocha em prolongado tempo de residência, e é bastante aceito no meio científico, como demonstra Carrilo-Rivera et al. (2002) e Kim e Jeong (2005). Contudo, Licht (2001) mostra uma origem ligada ao magmatismo alcalino no Serra Geral.

Nanni (2006) cita esta hipótese de filiação litogeoquímica para explicar as concentrações anômalas de fluoreto, que foram descritas por Fraga (1992) como atreladas a zonas de fluxo lento no SASG no Estado do Paraná. Outra hipótese está alicerçada no controle estrutural para a origem de fluoreto nas águas do SASG e baseia-se na conexão hidráulica entre diferentes aquíferos, por intermédio de estruturas tectônicas que possibilitam a ascensão de águas de aquíferos sotopostos ao SASG, neste caso as unidades pertencentes ao SAG. Como produtos têm-se águas com diversas condições de mistura (LISBOA E MENEGOTTO, 1997), (PORTELA FILHO et al, 2002), (MACHADO, 2006).

Registram-se, nas águas do aquífero Serra Geral, alguns casos de ocorrência de íon fluoreto em concentrações elevadas, a exemplo de Itambaracá, no norte do Estado, o que impede o aproveitamento do aquífero para abastecimento público (PINESE et al. 2001 e 2002).

Nos poços estudados em Ibiporã (Figura 6), o teor médio de fluoreto foi de $0,09 \mathrm{mg} / \mathrm{L}$, sendo que houve variação de 0,02 a 0,43 mg/L, destacando as máximas nos poços 25,26 e 27 do SASG, como citados. Tais resultados demonstram a heterogeneidade do aquífero Serra Geral, cujas águas permeiam as fraturas e estruturas interderrames desta formação geológica.

Figura 6 - Isolinhas da distribuição dos teores de fluoreto nas águas dos poços.

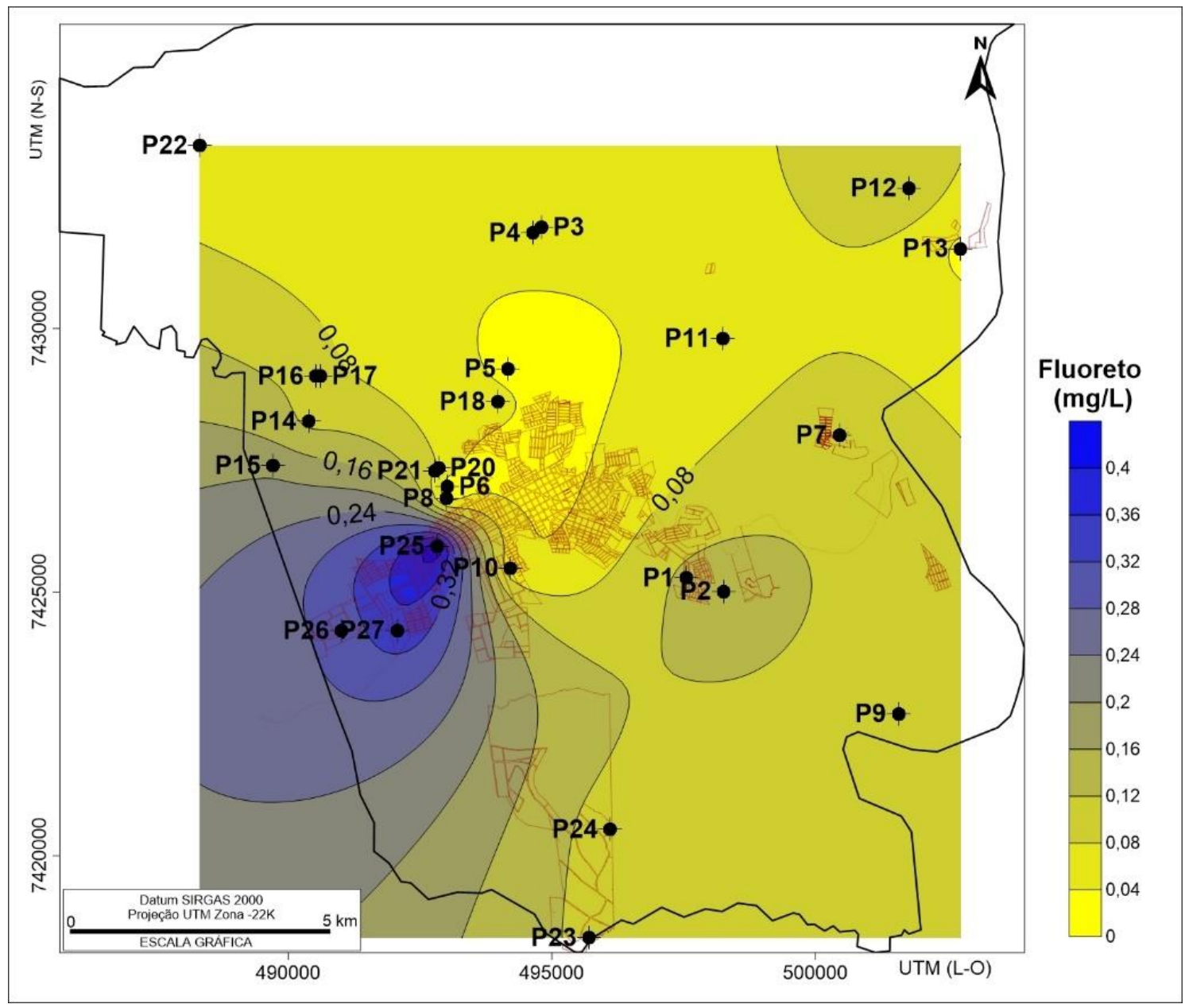

Fonte - CORCÓVIA (2013). 


\section{Nitrato}

Por ser bastante solúvel, o nitrato é dissolvido e transportado para as águas subterrâneas por ação da água da chuva. Essa situação é bastante comum em regiões que utilizam águas subterrâneas para abastecimento (ESTEVES, 1998).

A Portaria 2914/2011 do Ministério da Saúde estabelece como limite aceitável de padrão de potabilidade, o valor máximo de $10 \mathrm{mg} / \mathrm{L}$. Observa-se através da Tabela 2 que apenas o poço 15 (2,4 $\mathrm{mg} / \mathrm{L}$ ) apresentou concentração de nitrato estando com valor bem abaixo do permitido.

\section{Nitrito}

Os íons nitrito e o nitrato têm sido considerados contaminantes ambientais de larga escala. $O$ conhecimento dos teores dos íons nitrato e nitrito tem despertado grande interesse na sociedade, uma vez que a grande concentração tem causado problemas ao meio ambiente e a saúde humana (MELLO, 1999).

Os limites estão definidos pela Resolução CONAMA 396 (2008) e pela Portaria 2914/2011 do Ministério da Saúde que estabelece que os valores máximos dos íons nitrito é de 1,00 mg/L para consumo. Nas amostras observadas na Tabela 2, foi identificado a máxima de 0,20 mg/L e a mínima de $0,01 \mathrm{mg} / \mathrm{L}$, estando todas as amostras dentro do limite permitido (Figura 7 ).

Figura 7 - Isolinhas da distribuição dos teores de nitrito nas águas dos poços.

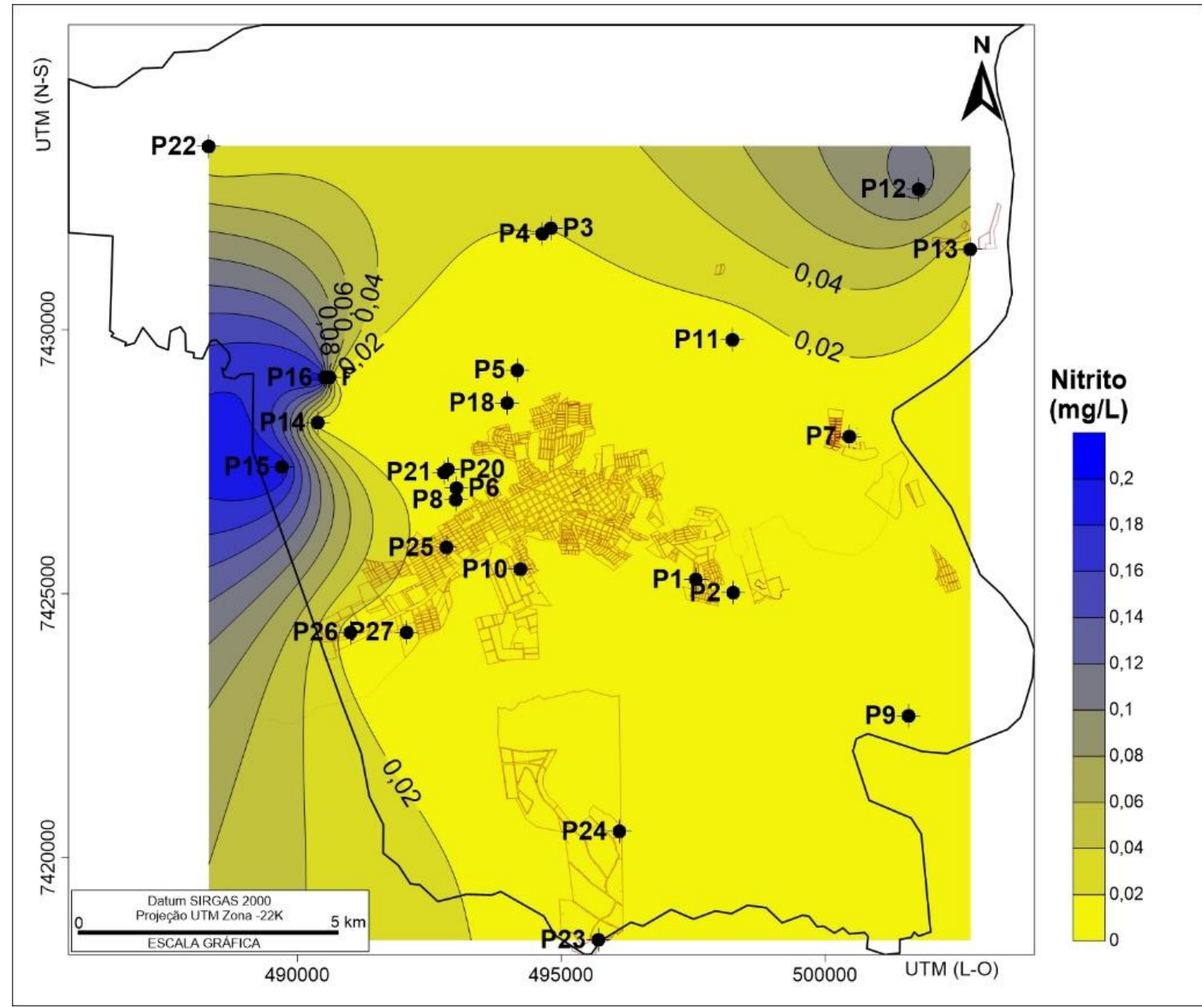

Fonte- CORCÓVIA (2013) 


\section{Sulfato}

Nota-se concentrações de sulfato em apenas 7 poços dos 27 analisados (Tabela 2), sendo que a máxima encontrada foi de $5,49 \mathrm{mg} / \mathrm{L}$ na área e a mínima de $0,29 \mathrm{mg} / \mathrm{L}$, a média da área foi de 3,58 $\mathrm{mg} / \mathrm{L}$, estando bem abaixo do limite permitido pela legislação brasileira (Figura 8). Segundo Corcóvia (2013), o mapa evidencia que cerca de $80 \%$ das amostras estão abaixo do limite de detecção da técnica empregada. A presença do ion sulfato é comum em águas do SAG com alto confinamento. Concentrações de sulfato além de $250 \mathrm{mg} / \mathrm{L}$ não são recomendadas para água de abastecimento público de acordo com a Resolução CONAMA 396/2008 (BRASIL, 2008).

Figura 8 - Isolinhas da distribuição dos teores de sulfato nas águas dos poços.

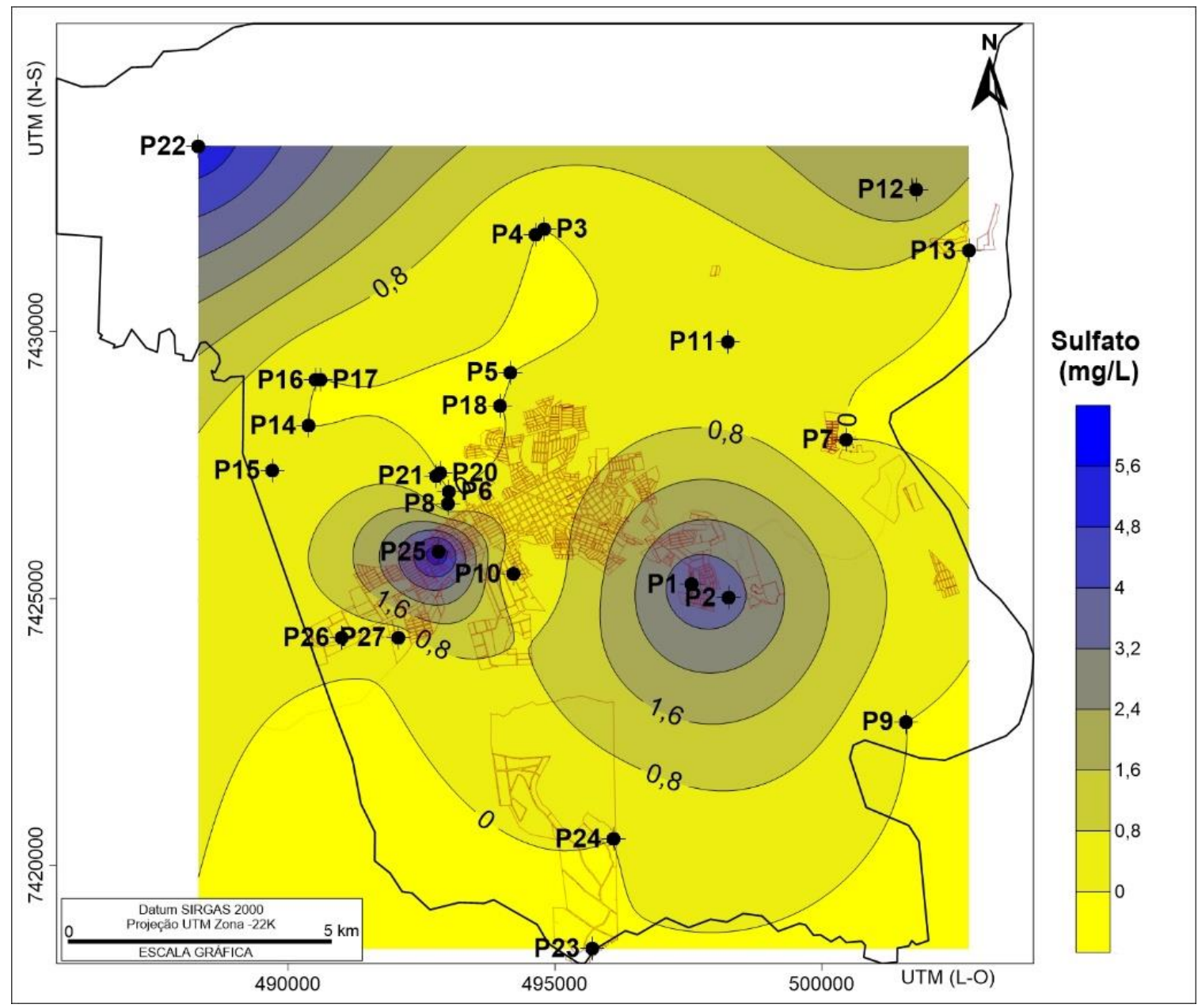

Fonte - CORCÓVIA (2013)

\section{Classificação química das águas subterrâneas na área}

Analisando-se o diagrama de Piper (Figura 9) com as águas dos poços da área, nota-se uma distribuição relativamente difusa, sustentando-se o caráter bicarbonatado cálcico. Tal composição coaduna-se relativamente com a tipologia química para águas deste aquífero na Bacia do Paraná, mencionada por Celligoi (1993). Raramente estão presentes os tipos sódicos.

Segundo Gastmans et al. (2016), duas facies hidroquímicas principais são reconhecidas: são os tipos $\mathrm{Ca}-\mathrm{Mg}-\mathrm{HCO}_{3}$ e $\mathrm{Na}-\mathrm{HCO}_{3}$, sendo estas bicarbonatadas calco-magnesianas e bicarbonatadas sódicas. Tal composição está associada a processos de dissolução dos minerais constituintes das rochas, que leva a saturação em calcita, observada em algumas amostras (GASTMANS et al, 2013).

Os poços 25 e 26, (pertencentes ao SASG) fogem a essas descrições. Essa diferença em relação ao
Caminhos de Geografia
Uberlândia
v. 20, n. 72
Dez/2019
p. $77-93$
Página 89 
modelo proposto se deve, provavelmente, a misturas com águas do Aquífero Guarani (P1 e P2).

De acordo com Celligoi (1993), as águas subterrâneas do Sistema Serra Geral podem ser classificadas como sendo bicarbonatadas cálcicas. Segundo Hindi (2007), as águas da região estudada podem ser classificadas como bicarbonatadas sódicas. As mesmas características são evidenciadas nas águas dos poços do SAG em Londrina.

Esta composição está relacionada à zona de médio confinamento, pois segundo Hindi (2007), para diferentes condições de confinamento, pode-se inferir um modelo geral de evolução das águas do SAG, que passariam de bicarbonatadas cálcicas a sódicas e, finalmente, a sulfatadas sódicas. Os poços 1 e 2 estão destacados no diagrama de piper evidenciando a sua composição. As águas captadas para o abastecimento público realizado no município são de boa qualidade para o consumo humano.

Figura 9 - Diagrama de Piper das amostras de água do SAG e SASG em Ibiporã-PR.

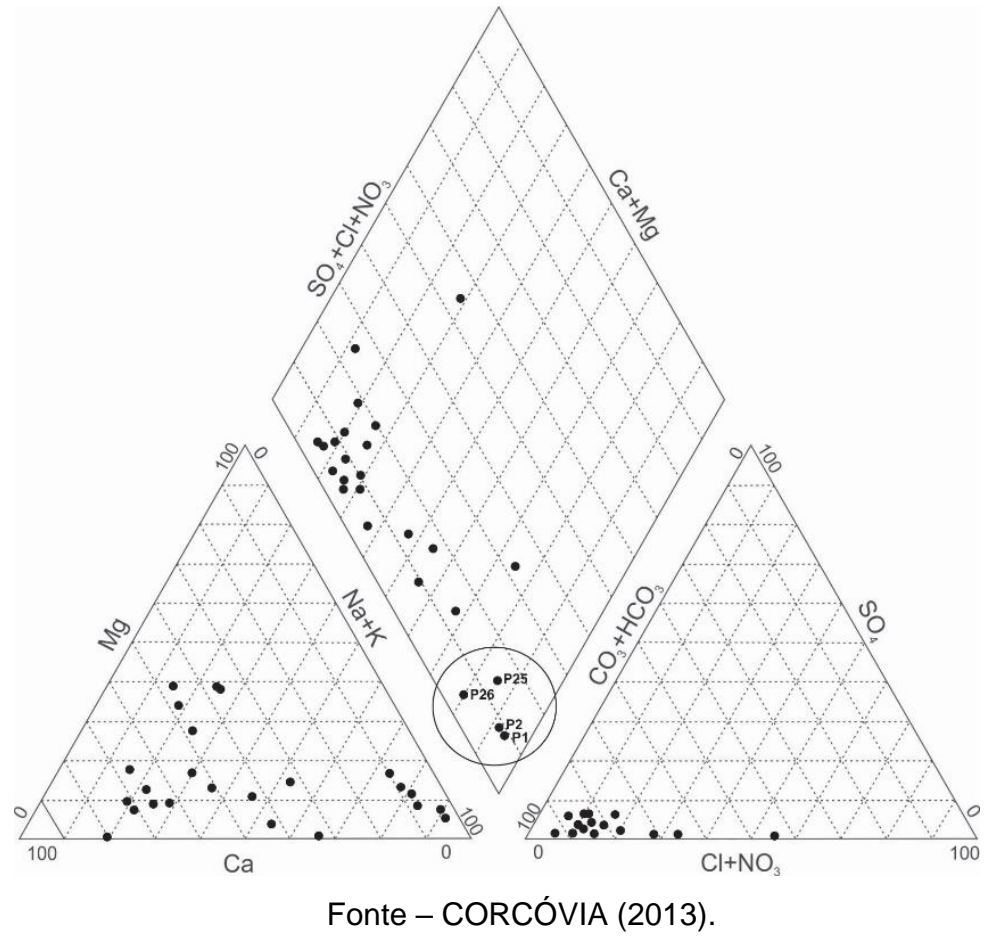

\section{CONSIDERAÇÕES FINAIS}

Os resultados obtidos nessas análises evidenciam que as amostras de águas subterrâneas dos dois aquíferos encontram-se em conformidade com a legislação vigente, atendendo às normas de potabilidade.

Foi observada a composição química da água subterrânea local para explicar uma possível conexão entre os dois aquíferos SAG e SASG, não tendo sido encontrada nenhuma anomalia química na qualidade da água subterrânea da área em estudo. Entretanto, alguns teores se destacaram em relação à média, como o fluoreto, cujo teor aparece aumentado nos poços do SAG e, também, nos poços 25, 26 e 27 do SASG, demonstrando a heterogeneidade deste aquífero na área.

O caráter bicarbonatado cálcico das águas do SASG pode ser evidenciado através da distribuição dos poços no diagrama de Piper. Tal composição se coaduna com a tipologia química para águas deste aquífero, exceto os poços 25 e 26 , os quais possuem composição bicarbonatada sódica pela mistura com águas do SAG, evidenciando uma conexão entre os aquíferos.

O município deve buscar uma política de gerenciamento de recursos hídricos subterrâneos, assim como para um embasamento legal que levem em conta a realidade das questões aqui abordadas, concretizando e possibilitando a ação de vigilância da qualidade das águas subterrâneas utilizadas
Caminhos de Geografia
Uberlândia
v. 20, n. 72
Dez/2019
p. 77-93
Página 90 
para o consumo humano, tanto em poços particulares como os de abastecimento público e que contribuam para a proteção desses recursos hídricos.

\section{AGRADECIMENTOS}

Ao CNPq e Fundação Araucária do Estado do Paraná, Brasil, pelo suporte financeiro através dos projetos do Convênio CNPq/Fundação Araucária: 61.0088/06-8 e Convênio Fundação Araucária/UEL: 063/08. Também dos projetos Fundação Araucária 15.880, 19.733 e 25.247.

\section{REFERÊNCIAS}

ALIEVI, A. A.; PINESE, J. P. P.; CELLIGOI, A. O processo de formação dos aquíferos e os impactos das atividades humanas: a importância da proteção das áreas de recarga de águas subterrâneas. Ciência Geográfica, v. XXIII, p. 590-597, 2019.

AMORE, L.; VARGAS, F. P. H.; OLIVERA, W. A. Figura ilustrativa do Sistema Aquífero Guarani como contribuição à gestão. In: II SIMPOSIO PARAGUAYO DE GEOLOGIA y III SIMPOSIO DE AGUAS SUBTERRÁNEAS Y PERFORACIÓN DE POZOS, Anais... Asunción, Paraguay. [CD Room], 2001.

ANA - Agência Nacional de Águas. SIH (Superintendência de Informações Hidrológicas). Águas Subterrâneas. Brasília, 2005.

ARAÚJO, L. M. et al. Acuífero Gigante del Mercosur en Argentina, Brasil, Paraguay y Uruguay: mapas hidrogeológicos de las formaciones Botucatu, Piramboia, Rosario del Sur, Buena Vista, Misiones y Tacuarembó. UFPR y Petrobras, 16p. Curitiba, Paraná - Brasil, 1995.

AYERS, R.S.; WESTCOT, D.W. Water quality for agriculture. 3rd. ed. Rome: FAO, 1985. 174p. (FAO. Irrigation and Drainage Paper, 29).

BRANCO, S. M. Água, Meio Ambiente e Saúde. In: REBOUÇAS, Aldo C; BRAGA, Benedito; TUNDISI, José, G. Águas doces no Brasil. São Paulo: Ed. Escrituras, 1999.

BRASIL. Ministério do Meio Ambiente. Conselho Nacional do Meio Ambiente. RESOLUÇÃo CONAMA no 396, de 3 de abril de 2008. Dispõe sobre a classificação e diretrizes ambientais para o enquadramento das águas subterrâneas e dá outras providências. Publicada no DOU nํㅜ 66 , de 7 de abril de 2008, Seção 1, páginas 64-68.

Ministério da Saúde. Portaria no 2914, de 14 de dezembro de 2011. Dispõe sobre os procedimentos de controle e de vigilância da qualidade da água para consumo humano e seu padrão de potabilidade. Diário Oficial da União, Brasília, DF. 14 dez. 2011, Seção 1, p. 39/46.

CARRILLO-RIVERA J.J., CARDONA A., EDMUNDS W.M. Use of abstraction regime and knowledge of hydrogeological conditions to control high-fluoride concentration in abstracted groundwater: San Luis Potosi basin, Mexico, Journal Hydrol, 2002, 261:24-47. https://doi.org/10.1016/S0022-1694(01)00566-2

CELLIGOI, A. Recursos Hídricos Subterrâneos da Formação Serra Geral em Londrina - PR. Dissertação (Mestrado). Instituto de Geociências, Universidade de São Paulo, SP. 1993. 83f.

CELLIGOI, A.; DUARTE, U. Aspectos hidrogeoquímicos da Formação Serra Geral em Londrina - PR. In: CONG. BRAS. ÁGUAS SUBT., 8, Recife, 1994. Anais...Recife: ABAS. p. 425-433.

CELLIGOI, A.; DUARTE, U. Hidrogeologia da Formação Serra Geral em Londrina - PR. Boletim Paranaense de Geociências, Curitiba, v. 45, n.1, p. 117-132, 1997.

CORCÓVIA, J. A.. Comportamento hidroquímico dos Aquíferos Guarani e Serra Geral no município de lbiporã - PR. Gestão de recursos hídricos subterrâneos. Dissertação (Mestrado em Geografia, Dinâmica Espaço Ambiental) - Universidade Estadual de Londrina, Londrina, 2013. 146 f.

ESTEVES, F. A. Fundamentos de Limnologia. 2a Ed. Rio de Janeiro, Interciência/ FINEP, 1998. $602 \mathrm{p}$. 
FEITOSA, F. A. C.; MANOEL FILHO, J.; FEITOSA, E. C.; DEMETRIO, J. G. A.. Hidrologia: Conceitos e aplicações. CPRM, LABHID, 2009. 812 p.

FRAGA,C. G. Introdução ao zoneamento do sistema aquífero Serra Geral no Estado do Paraná, São Paulo, 1986. Dissertação (Mestrado), USP.

Origem de Fluoreto em Águas Subterrâneas dos Sistemas Aquíferos Botucatu e Serra Geral da Bacia do Paraná, São Paulo-SP, 1992. Tese (Doutoramento), USP.

GASTMANS, D.; HUTCHEON, I.; CHANG, H. Q. Geochemical evolution of groundwater in a basaltic aquifer based on chemical and stable isotopic data: Case study from the Northeastern portion of Serra Geral Aquifer, São Paulo state (Brazil). Journal of Hydrology, vol. 535, Elsevier, 2016, pg. 598 - 611. https://doi.org/10.1016/i.jhydrol.2016.02.016

GASTMANS, D.; MENEGÁRIO, A. A.; MOURA C. C. Hidrogeoquímica das águas subterrâneas do Aquífero Serra Geral na porção centro sul do Estado de São Paulo. Águas Subterrâneas. V. 27 (3). ABAS, 2013, 27-44.

HINDI, E. C. Hidroquimica e hidrotermalismo do Sistema Aquífero Guarani no Estado do Paraná / Tese de Doutorado- Curitiba, 2007. xv, 153 f.

KIM, K.; JEONG, G. Y. Factors influencing natural occurrence of fluoride-rich ground waters: a case study in the southeastern part of the Korean Peninsula. Chemosphere 58:1399-1408. 2005. https://doi.org/10.1016/j.chemosphere.2004.10.002

LICHT, O.A.B. A geoquímica multielementar na gestão ambiental: identificação e caracterização de províncias geoquímicas naturais, alterações antrópicas da paisagem, áreas favoráveis à prospecção mineral e regiões de risco para a saúde no estado do Paraná, Brasil. 2001. 236 p. Tese (Doutorado em Geologia Ambiental)-Faculdade de Geologia, Universidade Federal do Paraná, Curitiba, 2001.

LISBOA, N. A.; MENEGOTTO, E. Condicionantes geoquímicos do sistema aquífero Serra Geral no Rio Grande do Sul, Brasil. Anais do V, SBGq, Salvador, p.134-136, 1997.

MACHADO, J. L. F. A redescoberta do Aquífero Guarani. Reportagem Scientific American Brasil, Abril, 2006. Edição 47, p. 1-6.

MARIMON, M. P. C. O flúor nas águas subterrâneas da formação Santa Cruz do Sul e Venâncio Aires, RS, Brasil. 2006. (Doutorado em Geociências). Departamento de Geoquímica, Universidade Federal do Rio Grande do Sul. Porto Alegre.

MELLO, C. C. de. Investigando traços de nitrato em águas naturais. Monografia apresentada ao Curso de Especialização em Ensino de Química Experimental para o 20. Grau, Setor de Ciências Exatas, Departamento de Química, Universidade Federal do Paraná. Curitiba, 1999. 30f.

NANNI, A. S.. O Flúor em águas subterrâneas do Sistema Aquífero Serra Geral no Rio Grande do Sul: origem e condicionamento geológico. In: SEMANA ACADÊMICA DOS ALUNOS DE PÓSGRADUAÇÃO EM GEOCIÊNCIAS, 1., 2006, Porto Alegre. Resumos... Porto Alegre: UFRGS, 2006. p. 101-104.

PINESE, J.P.P.; ALVES, J.C.; LICHT, O.A.B. Anomalias hidrogeoquímicas no município de Itambaracá (PR): resultados preliminares. CONGRESSO BRASILEIRODE GEOQUÏMICA, 8, Curitiba. Contribuições científicas, 2001.

PINESE, J.P.P; ALVES, J.C.; LICHT, O.A.B.; PIRES, E.O.; MARAFON, E. Características geoquímicas naturais da água de abastecimento público da porção extremo norte do Estado do Paraná, Brasil. CONGRESSO BRASILEIRO DE GEOLOGIA, 41, João Pessoa. Anais. João Pessoa, 2002.

PORTELA FILHO CV, FERREIRA FJF, ROSA FILHO EF, BUCHMANN AC AND ROSTIROLLA SP. Estudo preliminar da conexão entre os Aquíferos Serra Geral e Guarani com base em dados aeromagnetométricos e hidroquímicos. In: Congresso Brasileiro de Águas Subterrâneas, 12. 
Florianópolis, SC, Brasil.2002.

PREFEITURA MUNICIPAL DE IBIPORÃ. Base cartográfica Urbana, 2017. Disponível em: <http:// http://www.ibipora.pr.gov.br/pagina/1166/obras-e-viacao >. Acesso em: 20 nov. 2018.

REBOUÇAS, A. C. Diagnóstico do setor de hidrogeologia. Caderno técnico. São Paulo. ABAS, 1996. $46 \mathrm{p}$.

REBOUÇAS, A. C.; FRAGA, C.G. Hidrogeologia das rochas vulcânicas do Brasil. Ver. De Águas Subterrâneas, ㄲo12, 1988, ABAS. https://doi.org/10.14295/ras.v12i1.11282

REGINATO, P. A. R., AHLERT, S.; SCHNEIDER, V. E. Caracterização hidroquímica do Sistema Aquífero Serra Geral na região nordeste do Rio Grande do Sul. Águas Subterrâneas. V. 27 (1). ABAS, 2013, 65-78. https://doi.org/10.14295/ras.v27i1.27061

RICE, E. W.; BAIRD, R. B.; EATON, R. B.; CLESCERI, L. S. Stantard Methods for the Examination of Water and Wastewater, $22^{\text {nd }}$ Ed., American Public Health Association, WEF, AWWA. Washington, DC, 2012.

ROSA FILHO, E. F.; SALAMUNI, R.; BITTENCOURT, A. V. L. Contribuição ao estudo das águas subterrâneas nos basaltos no Estado do Paraná. Boletim Paranaense de Geociências, n 37, 1987. p. 22-52.

ROSA FILHO, E.F da, HINDI, L. E. M; BITETENCOURT, A. V. L. As águas subterrâneas no Estado do Paraná. Curitiba: ed. Do Autor, 2010. 145 p.

TAMER, M. N. Fluorosis. Encyclopedia of Environmental Health, $2^{\text {nd }}$. Edition, Elsevier. 2019. Pages 51-56. https://doi.org/10.1016/B978-0-12-409548-9.10663-3

Recebido em: 02/05/2018

Aceito para publicação em: 26/11/2019 